\title{
Individualized strategy for clopidogrel suspension in patients undergoing off-pump coronary surgery for acute coronary syndrome: A case-control study
}

\author{
Vito Mannacio, MD, ${ }^{\mathrm{a}}$ Pascal Meier, MD, ${ }^{\mathrm{b}, \mathrm{c}}$ Anita Antignano, MD, ${ }^{\mathrm{d}}$ Luigi Di Tommaso, MD, \\ Vincenzo De Amicis, MD, ${ }^{a}$ and Carlo Vosa, MD $^{\mathrm{a}}$
}

\begin{abstract}
Objective: An increasing number of patients presenting for urgent coronary surgery have been exposed to clopidogrel, which constitutes a risk of bleeding and related events. Based on the wide variability in clopidogrel response and platelet function recovery after cessation, we evaluated the role of point-of-care platelet function testing to define the optimal time for off-pump coronary artery bypass graft (CABG) surgery in a case-control study.
\end{abstract}

\begin{abstract}
Methods: Three equally matched groups (300 patients in total) undergoing isolated off-pump CABG for acute coronary syndrome were compared. Group A were treated with clopidogrel and prospectively underwent a strategy guided by platelet function testing. Outcomes were compared with 2 propensity score matched groups: group $\mathrm{B}$ underwent $\mathrm{CABG}$ after the currently recommended 5 days without clopidogrel; group $\mathrm{C}$ were never exposed to clopidogrel.

Results: Patients in group A had reduced postoperative bleeding compared with those in group B $(523 \pm 202 \mathrm{~mL}$ vs $851 \pm 605 \mathrm{~mL} ; P<.001$ ) and a lower number of units packed red blood cells (PRBCs) transfused during the postoperative hospital stay $(1.2 \pm 1.6$ units vs $1.9 \pm 1.8$ units; $P=.004)$. Postoperative bleeding and the number of units of PRBCs transfused were similar in group A and group C. There was no difference in blood-derived products and platelet consumption, mortality, or the need for reoperation among the groups. Patients in group A waited $3.6 \pm 1.7$ days for surgery. The strategy used for group A saved 280 days of hospital stay in total.

Conclusions: The strategy guided by platelet function testing for off-pump CABG offers improved guidance for optimal timing of CABG in patients treated with clopidogrel. This strategy significantly reduces postoperative bleeding and blood consumption, and has a shorter waiting time for surgery than current clinical practice. (J Thorac Cardiovasc Surg 2014;148:1299-306)
\end{abstract}

The current 2011 American College of Cardiology Foundation (ACCF)/American Heart Association (AHA)/Society for Cardiovascular Angiography and Interventions (SCAI) guidelines for percutaneous coronary intervention (PCI) recommend the administration of a loading dose of clopidogrel in patients undergoing PCI (class I indication) and dual antiplatelet therapy ideally for up to 12 months with additional aspirin after PCI with stents for acute coronary syndrome (ACS) or non-ACS (class I indication). ${ }^{1}$ Recently, 2012 ACCF/AHA guidelines for the management of unstable angina/non-ST-elevation myocardial infarction

\footnotetext{
From the Department of Cardiac Surgery, ${ }^{\mathrm{a}}$ University of Naples Federico II, Naples, Italy; Divisions of Cardiology and Cardiac Surgery, ${ }^{\mathrm{b}}$ Yale Medical School, New Haven, Conn; Cardiology, ${ }^{\mathrm{c}}$ University College London Hospital, London, United Kingdom; Department of Cardiology, ${ }^{\mathrm{d}}$ Azienda Ospedaliera Santobono-Pausillipon, Naples, Italy.

Disclosures: Authors have nothing to disclose with regard to commercial support.

Received for publication July 26, 2013; revisions received Oct 31, 2013; accepted for publication Dec 5, 2013; available ahead of print Feb 4, 2014.

Address for reprints: Vito Mannacio, MD, Via S. Domenico 62, 80127 Naples, Italy

(E-mail: vitomannacio2@libero.it).

$0022-5223 / \$ 36.00$

Copyright (c) 2014 by The American Association for Thoracic Surgery

http://dx.doi.org/10.1016/j.jtcvs.2013.12.011
}

suggested aspirin and clopidogrel for convalescent and long-term therapy for patients treated medically (class I indication). ${ }^{2}$ As a consequence, an increasing number of patients who present for cardiac surgery are receiving antiplatelet treatment with clopidogrel and are at risk of bleeding and bleeding-related complications.

The pharmacokinetics and pharmacodynamics of clopidogrel indicate that platelet inhibition decreases gradually to pretreatment levels $\sim 1$ week after treatment is terminated. ${ }^{3}$ Accordingly, current ACC/AHA guidelines recommend stopping clopidogrel at least 5 days before surgery in elective patients referred for coronary artery bypass graft (CABG) surgery to reduce bleeding, usage of blood products, and related complications. ${ }^{4,5}$ Data from the CRUSADE initiative reported that an increasing proportion of patients who need urgent surgery for ACS are exposed to clopidogrel and may be at risk for cardiac events while awaiting surgery after therapy withdrawal. ${ }^{6}$ The optimal management of these patients is unclear and has been matter of debate in recent years.

Most studies advise against surgery within 24 hours after discontinuation of clopidogrel, if the patient is stable, to avoid the significant risk of major bleeding complications. ${ }^{4,7}$ 


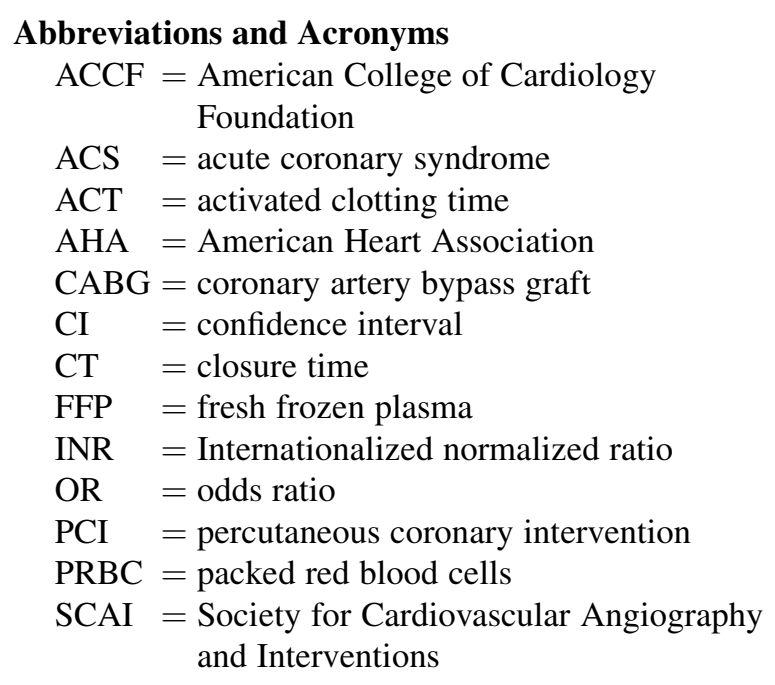

However, data on bleeding risk if CABG is performed between 24 hours and 5 days after clopidogrel cessation are conflicting. Some studies suggested that a 3-day delay could suffice to avoid bleeding risk and obtain safe outcomes. ${ }^{7-10}$ In contrast, other investigators reported a significantly increased bleeding risk if CABG is performed within 5 days of clopidogrel cessation. ${ }^{11,12}$ These different results can likely be attributed to the considerable intraand interindividual variability of clopidogrel-induced antiplatelet response; some individuals have suboptimal platelet inhibition despite an adequate dosage of clopidogrel, whereas others have delayed recovery of platelet function after clopidogrel cessation. ${ }^{3}$

This study evaluated the possibility of reducing postoperative blood loss and blood product consumption in patients treated with clopidogrel undergoing urgent CABG for ACS. We hypothesized that individualized point-of-care platelet function testing could provide a useful guide to optimal timing for surgery after discontinuation of antiplatelet therapy.

\section{METHODS}

This case-control study was designed according to the STROBE (Strengthening the Reporting of Observational Study Epidemiology) statement. The protocol was approved by the institutional ethics committee. All patients were enrolled prospectively and provided written informed consent. For the control patients, selected retrospectively, the institutional review board approved the use of the database for research; hence, the need for individual patient consent was waived for this study. All patients had preliminarily granted permission for the use of their medical records for research purposes.

\section{Patient Population and Study Groups}

From October 2012 to February 2013, 100 consecutive patients (group A) scheduled for CABG surgery for ACS at the Department of Cardiac Surgery of University Federico II in Naples, who were under clopidogrel treatment (single therapy or combined with aspirin $100 ; 325 \mathrm{mg} / \mathrm{d}$ ) and met the inclusion criteria, were prospectively enrolled in the study. The exclusion criteria are listed in Table 1. Clopidogrel was suspended once the indication for CABG was established and the waiting time for surgery was guided by a point-of-care platelet function test. According to guidelines, aspirin was not discontinued before surgery. ${ }^{4,5}$

Group A was compared with 2 control groups based on 1:1:1 matching (100 patients in each group). These patients underwent CABG surgery between January and September 2012. Group B consisted of 100 patients who underwent $\mathrm{CABG}$ for ACS, were taking a daily oral dose of clopidogrel $(75 \mathrm{mg} / \mathrm{d})$ alone or in addition to aspirin $(100-325 \mathrm{mg} / \mathrm{d})$ preoperatively, and were managed in accordance with current guidelines; clopidogrel was suspended 5 days before surgery, whereas aspirin was continued. ${ }^{4,5}$ Group $\mathrm{C}$ consisted of 100 controls who underwent elective $\mathrm{CABG}$ and were not taking thienopyridine therapy. Group B and group C were collected retrospectively from our institutional database To obtain 3 homogeneous groups and eliminate confounding bias caused by unequal distribution of clinical and demographic characteristics among groups, patient selection was performed by propensity score matching.

The main clinical and demographic characteristics of the patients are described in Table 2. Group A and group B were homogeneous for age, sex, clinical history, clinical presentation, medical therapy, preoperative risk factors, coronary lesions, surgical procedures, and risk factors for bleeding. Group $\mathrm{C}$ was mainly different for clinical presentation, preoperative risk factors, medical therapy, overall risk factors for bleeding and, therefore, was highly significant as control.

All surgical procedures were performed off-pump by the same group of experienced surgeons through a median sternotomy. The surgical technique was similar for all patients. The left thoracic artery was the conduit of choice. The right thoracic artery and the radial artery were used whenever indicated. Thoracic arteries were harvested in skeletonized fashion. Before anastomosis, patients received $150 \mathrm{IU}$ heparin $/ \mathrm{kg}$ body weight to obtain a kaolin activated clotting time (ACT) of longer than 400 seconds. Protamine sulfate was administered to reverse the heparin effect with the goal of normalizing the ACT. A cell salvage device was used during the surgery in all cases and salvaged blood was reinfused. Perioperative management was according to our institutional standards and was similar in all patients. Dual antiplatelet therapy with aspirin $100 \mathrm{mg}$ and clopidogrel $75 \mathrm{mg}$ was started when postoperative chest tube drainage was less than $50 \mathrm{~mL} / \mathrm{h}$ for 2 consecutive hours and was continued daily. ${ }^{13}$

Complete blood count and a coagulation panel, including prothrombin time, partial thromboplastin time, thrombin time, and blood fibrinogen concentrations, were analyzed preoperatively immediately on arrival at the intensive care unit and every 6 hours of the first 2 postoperative days or more frequently if required. To recognize heparin rebound or inadequate heparin neutralization, ACT was analyzed immediately on arrival at the intensive care unit, every 3 hours for the first 12 hours, and every 6 hours thereafter. Further evaluations of the ACT followed the administration of protamine sulfate given with the goal of normalizing the ACT. Chest tube drainage was registered at $6,12,24$, and 36 postoperative hours. Blood loss volume per patient was assessed after the first 36 postoperative hours (shed blood was never reinfused). Postoperative transfusion rates and quantities were recorded for the principal blood product types, including packed red blood cells (PRBCs), platelets, fresh frozen plasma (FFP), and cryoprecipitate. Factor VII or other agents were not used routinely.

Transfusion of blood products and management of postoperative bleeding were determined by following an institutional algorithm. PRBCs were transfused when the patient's blood hemoglobin level was less than $6 \mathrm{~g} / \mathrm{dL}$ for patients younger than 65 years or of less than $7 \mathrm{~g} / \mathrm{dL}$ for patients older than 65 years. When the hemoglobin level was between 7 and 10 $\mathrm{g} / \mathrm{dL}$, PRBCs were transfused in cases of bleeding with symptoms of hypovolemia, decreased oxygen saturation in mixed venous blood unrelated to systemic oxygenation, and when signs of myocardial ischemia ere present. ${ }^{14}$ Postoperative bleeding was managed as follows: (1) preliminary 
TABLE 1. Exclusion criteria

\begin{tabular}{l} 
History of cardiac surgery \\
Emergency surgery \\
Additional cardiac procedures \\
Additional surgical procedures \\
Contraindications for off-pump approach \\
Absolute \\
$\quad$ Poor target vessels \\
$\quad$ Likelihood of requiring endarterectomy \\
$\quad$ Atherosclerotic ascending aorta \\
$\quad$ Severe mitral regurgitation \\
Relative \\
$\quad$ Need for extensive revascularization of the posterior wall in patient \\
$\quad$ with cardiomegaly and congestive heart failure \\
Conversion to cardiopulmonary bypass (mechanical and/or electrical \\
instability in the operating theatre) \\
Recent exposure to a warfarin derivate \\
Recent exposure to platelet glycoprotein IIb/IIIa inhibitors \\
Hematocrit $<33 \%$ \\
Platelet count $<100,000$ mm 3 \\
Preexisting bleeding disorders \\
Active liver disease or increased liver enzyme levels \\
Renal failure (serum creatinine $>2.0 \mathrm{mg} / \mathrm{dL}$ ) \\
Obesity (body mass index $\geq 30 \mathrm{~kg} / \mathrm{m}^{2}$ ) \\
\hline
\end{tabular}

assessment of ACT and correction by protamine sulfate; (2) FFP if the patient's internationalized normalized ratio (INR) was greater than 1.3 ; (3) 10 units of cryoprecipitate if the blood fibrinogen level was less than $1.5 \mathrm{~g} / \mathrm{dL}$; (4) platelet concentrate if bleeding continued despite a normal ACT, INR, and blood fibrinogen level or when the platelet count was less than 50,000 $\mathrm{mm}^{3}$. Indications for chest exploration were bleeding more than $500 \mathrm{~mL}$ at $1 \mathrm{~h}$, greater than $400 \mathrm{~mL} / \mathrm{h}$ for 2 consecutive hours, greater than $200 \mathrm{~mL} / \mathrm{h}$ for 3 to 4 consecutive hours, greater than $1000 \mathrm{~mL}$ in the first 3 hours after surgery or in the case of cardiac tamponade.

\section{Point-of-Care Platelet Function Evaluation}

Although light transmittance aggregometry is still regarded as the method of choice for platelet function assessment, it is neither standardized nor user friendly for point-of-care evaluations. In the present study, the PFA-100 System (Siemens, Marburg, Germany) with the INNOVANCE PFA P2Y cartridge was used as a simple and rapid point-of-care tool for platelet function assessment. Platelet function was evaluated as the time taken for blood to block a membrane coated with adenosine diphosphate, prostaglandin E1, and calcium chloride. The time required to occlude the central aperture (diameter, $100 \mu \mathrm{m}$ ), resulting in the cessation of blood flow, was defined as the closure time (CT); the maximum value for CT was determined by the maximum measurement time of 300 seconds. CT values of 106 seconds or less were considered to indicate good platelet reactivity, whereas values exceeding 106 seconds were viewed as reduced reactivity. ${ }^{15,16}$ Blood samples were stored undisturbed at +15 to $+25^{\circ} \mathrm{C}$ and processed within 2 hours. All patients included in group A underwent daily assessment of platelet function. Surgery was performed when CT values were suggestive of recovered platelet function ( $\leq 106$ seconds).

\section{Definitions and End Points}

The primary end point was the volume of chest tube output during the first 36 hours. Secondary end points were the need for blood products and hospital length of stay. The adverse events rates (reexploration for bleeding, stroke, myocardial infarction, renal failure, and need for hemodialysis, sepsis, sternal wound infections, and death) were indicative of clinical outcome.
Preoperative risk stratification was performed by the logistic European system for cardiac operative risk evaluation (EuroSCORE). Assessment of priority for surgery was defined as follows: operation was considered an emergency if the medical factors relating to the patient's cardiac disease dictated that surgery should be performed within hours to prevent morbidity or death; operation was considered urgent if the medical factors required the patient to stay in the hospital for an operation before discharge; operation was considered elective if the clinical situation allowed discharge from the hospital with readmission at a later date. ${ }^{4-17}$ Renal dysfunction was defined as increased serum creatinine value of $2.5 \mathrm{mg} / \mathrm{dL}$ or greater. Acute myocardial infarction was diagnosed when the 3 criteria indicated by the Joint European Society of Cardiology/ACCF/AHA/World Heart Federation guidelines were fulfilled. ${ }^{18}$ The low output syndrome was diagnosed as previously described. ${ }^{19}$

\section{Statistical Analysis}

Previous observational and randomized studies were used to calculate the sample size needed to detect significant differences for the end points. On the assumption that a reduction of at least $40 \%$ in mean perioperative blood loss, ${ }^{7,9} 75$ patients were required in each group at an $\alpha$ value of 0.05 and $80 \%$ power. Similarly, given that postoperative PRBC transfusion rates increased by $35 \%$ in patients who underwent off-pump CABG and in whom clopidogrel was stopped less than 5 days before surgery, ${ }^{7,9-12}$ to detect an absolute reduction of a 2-unit difference in PRBC transfusion rates, 98 patients were required in each group at an $\alpha$ value of 0.05 and $80 \%$ power.

To reduce the effect of potential confounders caused by demographic and clinical variability among the groups, case-control matching was used to evaluate the impact of clopidogrel on the primary end point. Patients from group A were individually matched (1:1 ratio) to a set of patients treated according to current guidelines (group B) and to a set of controls who underwent elective CABG and naive to clopidogrel (group C). A combination of the SAS/STAT logistic procedure and an SAS \% GMATCH Macro program was used to match cases to controls. Propensity scores were calculated with a logistic regression model including the following dichotomous variables: sex, hypertension, diabetes, lung disease, peripheral vascular disease, history of myocardial infarction, history of stent, preoperative use of unfractionated heparin, preoperative use of low molecular weight heparin, preoperative aspirin dose $100 \mathrm{mg}$, preoperative aspirin dose $325 \mathrm{mg}$, increased levels of cardiac biomarkers, unstable angina, electrocardiograph signs, single or double internal thoracic artery use, saphenous vein graft use, and radial artery use. Age, body mass index, left ventricular ejection fraction, and logistic EUROscore were incorporated in the model as continuous variables. Matching was done without replacement, based on caliper matching with a prespecified maximum caliper distance of 0.2 of the standard deviation of the logit of the propensity score. If more than 1 unmatched control matched equally well to a case, the control was selected at random.

Data were tested for normal distribution by the Anderson-Darling test. Categorical variables were reported by frequencies or percentages. Continuous variables were summarized by mean and standard deviation and/or median and interquartile range (25th to 75 th percentile). Comparison between continuous variables was made by means of the Student $t$ test. The Wilcoxon signed rank test was used for variables not normally distributed Categorical variables were compared using $\chi^{2}$ statistics or the Fisher exact test if appropriate. Analysis of variance with correction for serial measurements or the Kruskal-Wallis test for non-Gaussian data distribution was performed for bleeding evaluation.

Predictors of blood transfusion (need for 3 or more units of PRBCs) were evaluated in the entire population of 300 patients. Variables included in the model were age greater than 65 years, female sex, ejection fraction less than $40 \%$, ACS, preoperative heparin and/or aspirin, number of distal anastomoses, preoperative clopidogrel management (group A or B), and freedom from preoperative treatment with clopidogrel (group C). 
TABLE 2. Demographic and clinical characteristics

\begin{tabular}{|c|c|c|c|c|c|}
\hline & Group A $(n=100)$ & Group B $(\mathbf{n}=100)$ & Group C $(n=100)$ & $P^{*}$ & $\boldsymbol{P} \dagger$ \\
\hline Mean age, $\mathrm{y} \pm \mathrm{SD}$ & $63 \pm 11$ & $61 \pm 12$ & $60 \pm 11$ & .2 & .5 \\
\hline Male, $n$ & 65 & 67 & 65 & .9 & 1 \\
\hline Mean BMI, $\mathrm{kg} / \mathrm{m}^{2} \pm \mathrm{SD}$ & $24 \pm 4.1$ & $25 \pm 3.3$ & $25 \pm 2.7$ & 6 & 1 \\
\hline Hypertension, $\mathrm{n}$ & 62 & 65 & 58 & .7 & 6 \\
\hline Diabetes, $\mathrm{n}$ & 12 & 13 & 15 & .9 & .8 \\
\hline Lung disease, $\mathrm{n}$ & 18 & 20 & 16 & .8 & .8 \\
\hline Peripheral vascular disease, $\mathrm{n}$ & 10 & 12 & 12 & .8 & .8 \\
\hline History of MI, n & 42 & 39 & 30 & .7 & .1 \\
\hline History of stent, $\mathrm{n}$ & 58 & 62 & 5 & .6 & $<.001$ \\
\hline Mean LVEF, $\% \pm$ SD & $45 \pm 16$ & $48 \pm 15$ & $50 \pm 12$ & .1 & .001 \\
\hline Log EUROscore, median (IQR) & $4(2-5)$ & $4(2-5)$ & $3(1.8-5)$ & 1 & .01 \\
\hline Unfractionated heparin, $24 \mathrm{~h}$ preoperatively, $\mathrm{n}$ & 60 & 65 & 0 & .5 & \\
\hline LMW heparin, $\mathrm{n}$ & 13 & 15 & 10 & .8 & .6 \\
\hline \multicolumn{6}{|l|}{ Aspirin dose } \\
\hline $100 \mathrm{mg}, \mathrm{n}$ & 60 & 63 & 45 & .9 & .7 \\
\hline $325 \mathrm{mg}, \mathrm{n}$ & 9 & 8 & 2 & 1 & .06 \\
\hline \multicolumn{6}{|l|}{ Clinical presentation } \\
\hline Increased cardiac biomarkers, $\mathrm{n}$ & 50 & 52 & & .9 & \\
\hline Unstable angina, $\mathrm{n}$ & 40 & 42 & & .9 & \\
\hline ECG signs, $n$ & 38 & 39 & & 1 & \\
\hline \multicolumn{6}{|l|}{ Laboratory data } \\
\hline Creatinine, $\mathrm{mg} / \mathrm{dL}$ & $1.06 \pm 0.3$ & $1.0 \pm 0.2$ & $1.0 \pm 0.2$ & 1 & 1 \\
\hline Hematocrit & $38 \pm 6$ & $39 \pm 4$ & $40 \pm 3$ & 1 & .9 \\
\hline Platelet count, $10^{3} / \mathrm{mm}^{2}$ & $225 \pm 32$ & $231 \pm 38$ & $221 \pm 35$ & .2 & .3 \\
\hline ACT preoperative, $\mathrm{s}$ & $123 \pm 26$ & $130 \pm 28$ & $123 \pm 25$ & .06 & 1 \\
\hline ACT postoperative, $\mathrm{s}$ & $141 \pm 38$ & $148 \pm 42$ & $149 \pm 40$ & .2 & .1 \\
\hline INR, units & $1.1 \pm 0.5$ & $1.0 \pm 0.3$ & $1.1 \pm 0.3$ & .08 & 1 \\
\hline \multicolumn{6}{|l|}{ Operative data } \\
\hline Number of anastomosis/patient & $2.45 \pm 0.3$ & $2.5 \pm 0.28$ & $2.41 \pm 0.32$ & .4 & 6 \\
\hline Single ITA, $\mathrm{n}$ & 77 & 76 & 73 & 1 & 6 \\
\hline Double ITA, n & 20 & 20 & 25 & 1 & .5 \\
\hline SVG, n & 125 & 131 & 116 & .5 & .7 \\
\hline Radial artery, $\mathrm{n}$ & 25 & 23 & 26 & .8 & 1 \\
\hline
\end{tabular}

Values are means \pm SD or numbers except the logistic EUROscore, which is presented as the median and interquartile range (IQR). SD, Standard deviation; $B M I$, body mass index; $M I$, myocardial infarction; $L V E F$, left ventricular ejection fraction; $L M W$, low molecular weight; $E C G$, electrocardiogram; $A C T$, activated clotting time; $I N R$, international normalized ratio; ITA, internal thoracic artery; $S V G$, saphenous vein graft. $* P$ value for the comparison of group A versus group $\mathrm{B}$. $\dagger P$ value for the comparison of group A versus group C.

A nonparametric 2-tailed McNemar test was also used for dichotomous variables between the matched groups taking into account the nonindependent nature of matched data. The odds ratios and $95 \%$ confidence intervals investigating the independent role of point-of-care assay on primary and secondary end points, including the transfusion of multiple PRBCs units and quartile distribution for bleeding, were assessed by logistic regression. Statistical analyses were performed with SAS/STAT, version 9.1 (SAS Institute, Inc, Cary, NC), or with SPSS, version 13.0 for Windows (SPSS, Inc, Chicago, Ill).

\section{RESULTS}

\section{Point-of-Care Platelet Function Evaluation}

Each patient in group A underwent surgery when the CT value was restored. The mean interval between clopidogrel cessation and surgery was $3.64 \pm 1.7$ days (median, 4 days; interquartile range, $3-4)$. Twenty-three patients (23\%) had a CT value of 106 seconds or less despite clopidogrel therapy and were operated immediately without any waiting period.
Conversely, the waiting period was 5 days or more in 18 patients $(18 \%)$ as a result of their platelet function test (Figure 1).

\section{Primary and Secondary End Points}

Univariate determinants of 3 or more units of PRBC postoperative blood transfusion using all 300 study patients were age greater than 65 years, female gender, ACS, preoperative aspirin use, number of distal anastomoses, and belonging to group B. Multivariate analysis confirmed only age greater than 65 years (odds ratio [OR], 3.6; 95\% confidence interval $[\mathrm{CI}], 1.5-8.3 ; P<.001)$, preoperative aspirin (OR, 1.3; 95\% CI, 1.0-2.1, $P=.04$ ), and belonging to group $\mathrm{B}(\mathrm{OR}, 2.1 ; 95 \% \mathrm{CI}, 1.3-3.8 ; P<.001)$ as independent predictors for the need of 3 or more units of PRBCs.

Postoperative bleeding and the need for blood products transfusion are presented in Table 3. In the multivariable 


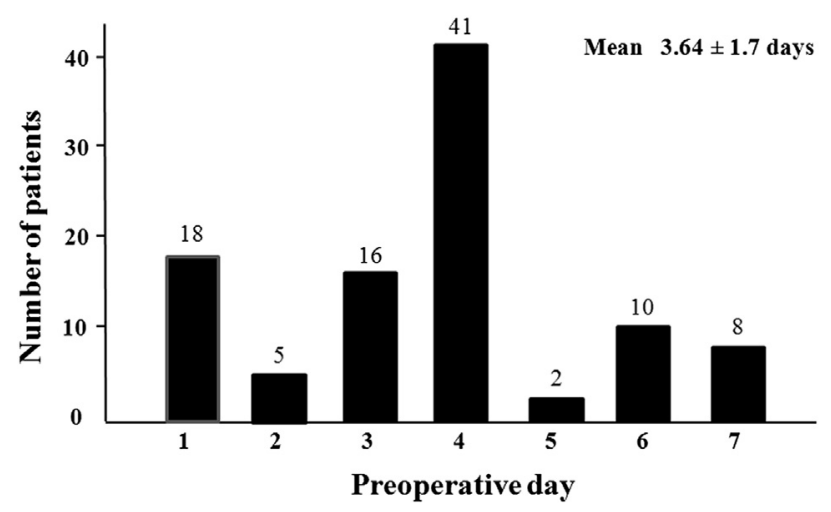

FIGURE 1. Distribution of preoperative waiting time in group A.

logistic regression analysis adjusted for the variables listed in Table 1, the odds of postoperative blood loss more than the median value was 2.7 times $(95 \%$ CI, 1.61-3.62; $P=.01)$ greater in group $\mathrm{B}$. The odds of receiving a PRBC transfusion and of receiving 3 or more units of PRBCs were 1.9 times $(95 \%$ CI, $1.38-2.52 ; P=.01)$ and 2.3 times $(95 \% \mathrm{CI}, 1.52-3.52 ; P=.01)$ greater in group B. The McNemar test confirmed the significant prevalence of the need for PRBCs (OR, 1.6; 95\% CI, 1.0-2.6; $P=.01$ ) or for 3 or more units of PRBCs (OR, 1.3; 95\% CI, 1.1-1.4; $P=.03$ ) in group B. Overall, $20 \%$ more patients and on average 1 more unit of PRBCs were transfused in group B versus group A or C. In contrast, FFP, cryoprecipitate, and platelets were seldom transfused independently from the study groups. The predicted likelihood of receiving FFP (OR, 0.8; 95\% CI, 0.3-2.1;P=.8) or platelet transfusion (OR, $0.6 ; 95 \%$ CI, $0.2-1.4 ; P=.3$ ) was not statistically significant among the groups.

The subgroup analysis of patients, stratified on quartile distribution of blood loss, revealed a significantly increased mean bleeding volume in the upper quartile of group B $(1820 \pm 217 \mathrm{~mL})$ compared with group A $(786 \pm 82 \mathrm{~mL})$ and group $\mathrm{C}(785 \pm 108 \mathrm{~mL})(P<.001)$. By contrast, the mean blood loss was similar among the groups in the lower quartiles (Figure 2). The number of units of PRBCs transfused was also significantly increased in the upper quartile of group $\mathrm{B}(4.5 \pm 1.2)$ compared with the upper quartiles of group A $(3.6 \pm 1.1)$ and group C $(3.8 \pm 1.5)(P=.008)$; there was no significant difference in blood products transfused in the lower quartiles. Patients in group B experienced more prolonged bleeding over the time compared with patients in group A and group C (Figure 3).

The impact of aspirin on postoperative bleeding was evaluated by a comparative analysis of chest tube drainage with respect to preoperative aspirin exposure. Chest tube drainage was similar in patients using aspirin and nonusers in group $\mathrm{A}(510 \pm 190 \mathrm{~mL}$ vs $530 \pm 200 \mathrm{~mL} ; P=.5)$, group $\mathrm{B}(840 \pm 590 \mathrm{~mL}$ vs $880 \pm 620 \mathrm{~mL} ; P=.7)$, and group C $(480 \pm 200 \mathrm{~mL}$ vs $500 \pm 210 \mathrm{~mL} ; P=.6)$.

Results on length of stay are reported in Table 3. Patients in group A saved $\sim 280$ days of total hospital stay versus patients in group B. At multivariate analysis, the variable postoperative length of hospital stay of 8

TABLE 3. Primary and secondary end points

\begin{tabular}{|c|c|c|c|c|c|}
\hline & Group A $(n=100)$ & Group B $(\mathbf{n}=100)$ & Group C $(n=100)$ & $P^{*}$ & $\boldsymbol{P} \dagger$ \\
\hline Total fluids, mean $\mathrm{mL} \pm \mathrm{SD}$ & $4880 \pm 550$ & $4790 \pm 650$ & $4750 \pm 600$ & .3 & .1 \\
\hline Blood loss, mean $\mathrm{mL} \pm \mathrm{SD}$ & $523 \pm 202$ & $851 \pm 605$ & $490 \pm 210$ & $<.001$ & .2 \\
\hline Median (IQR) & $500(350-700)$ & $600(400-1300)$ & $500(300-650)$ & $<.001$ & .7 \\
\hline \multicolumn{6}{|l|}{ Need for PRBCs } \\
\hline Number of patients & 44 & 65 & 47 & .004 & .7 \\
\hline Need for 1-2 units & 21 & 21 & 23 & 1 & .9 \\
\hline Need for 3 or more units & 23 & 44 & 24 & .002 & 1 \\
\hline Units/patient, mean $\pm \mathrm{SD}$ & $1.2 \pm 1.6$ & $1.9 \pm 1.8$ & $1.3 \pm 1.7$ & .004 & .6 \\
\hline Median (IQR) & $1(0-2)$ & $2(0-3)$ & $1(0-2)$ & .008 & 1 \\
\hline \multicolumn{6}{|l|}{ Need for FFP } \\
\hline Number of patients & 11 & 13 & 10 & .8 & 1 \\
\hline Units/patient, mean $\pm \mathrm{SD}$ & $4.8 \pm 1.2$ & $4.6 \pm 1.1$ & $4.4 \pm 1.8$ & .6 & .2 \\
\hline Median (IQR) & $3(2-5)$ & $3(2-5)$ & $3(2-5)$ & .5 & .09 \\
\hline \multicolumn{6}{|l|}{ Need for platelets } \\
\hline Number of patients & 12 & 16 & 10 & .5 & .8 \\
\hline \multicolumn{6}{|l|}{ Length of hospital stay, $\mathrm{d} \pm \mathrm{SD}$} \\
\hline Preoperative & $3.6 \pm 1.7$ & 5 & & $<.001$ & \\
\hline Postoperative in ICU & $2.2 \pm 1.2$ & $2.6 \pm 1.5$ & $2.1 \pm 0.9$ & .03 & .5 \\
\hline Postoperative, total & $8.7 \pm 2.1$ & $9.4 \pm 2.4$ & $8.2 \pm 1.6$ & .02 & .5 \\
\hline Total (pre- + postoperative) & $11.9 \pm 2.5$ & $14.7 \pm 2.2$ & & $<.001$ & \\
\hline Intubation time, $\mathrm{h} \pm \mathrm{SD}$ & $6.4 \pm 5.8$ & $7.5 \pm 5.1$ & $6.5 \pm 6.4$ & .1 & .9 \\
\hline
\end{tabular}

Values are numbers, mean $\pm \mathrm{SD}$ or median and interquartile range $(I Q R)$. SD, Standard deviation; $P R B C$, packed red blood cells; $F F P$, fresh frozen plasma; $I C U$, intensive care unit. $* P$ value for the comparison of group A versus group B. $\dagger P$ value for the comparison of group A versus group $\mathrm{C}$. 


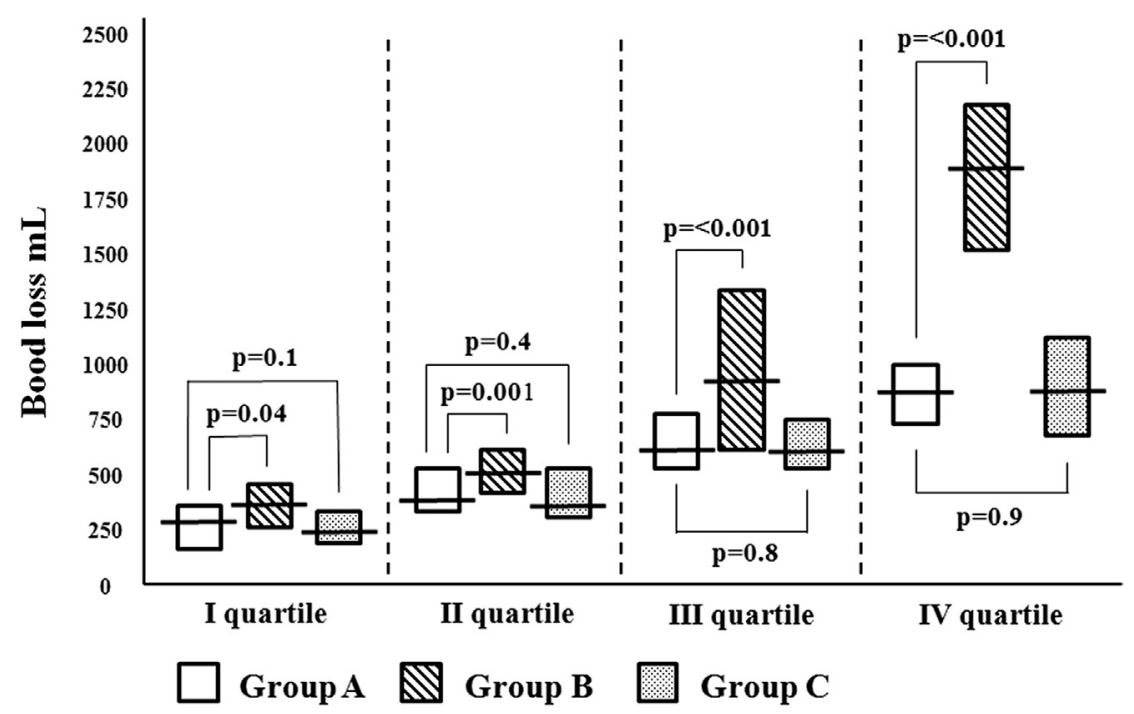

FIGURE 2. Postoperative chest tube drainage stratified for interquartile distribution. Box defines the interquartile range, with the mean indicated by the crossbar.

days or more was significantly related to the higher quartile of postoperative blood loss (OR, 2.5; 95\% CI, 1.1-5.5; $P=.02)$.

\section{Clinical Outcome}

Clinical outcome is reported in Table 4. Postoperative adverse events were not frequent enough to support statistically significant results in this trial.

One patient in group A and 2 in group B developed cardiogenic shock while awaiting surgery 3,2 , and 3 days after drug discontinuation; they were assisted by intraaortic balloon pumping and underwent subsequent emergency CABG. They were not evaluated further for the study.

\section{DISCUSSION}

This study challenges current guidelines by showing that a strategy based on individualized point-of-care platelet function measurements can reduce postoperative bleeding and blood product consumption as well as the waiting time to surgery. On average, this strategy resulted in an overall $38 \%$ shortening of the recommended preoperative waiting period for patients on clopidogrel treatment (mean, $3.6 \pm 1.7$ days vs 5 days per patient) and in a significant reduction of postoperative bleeding and blood product consumption. In contrast, blood loss and transfusion requirements were similar in patients managed by daily platelet function testing and in controls. Because controls

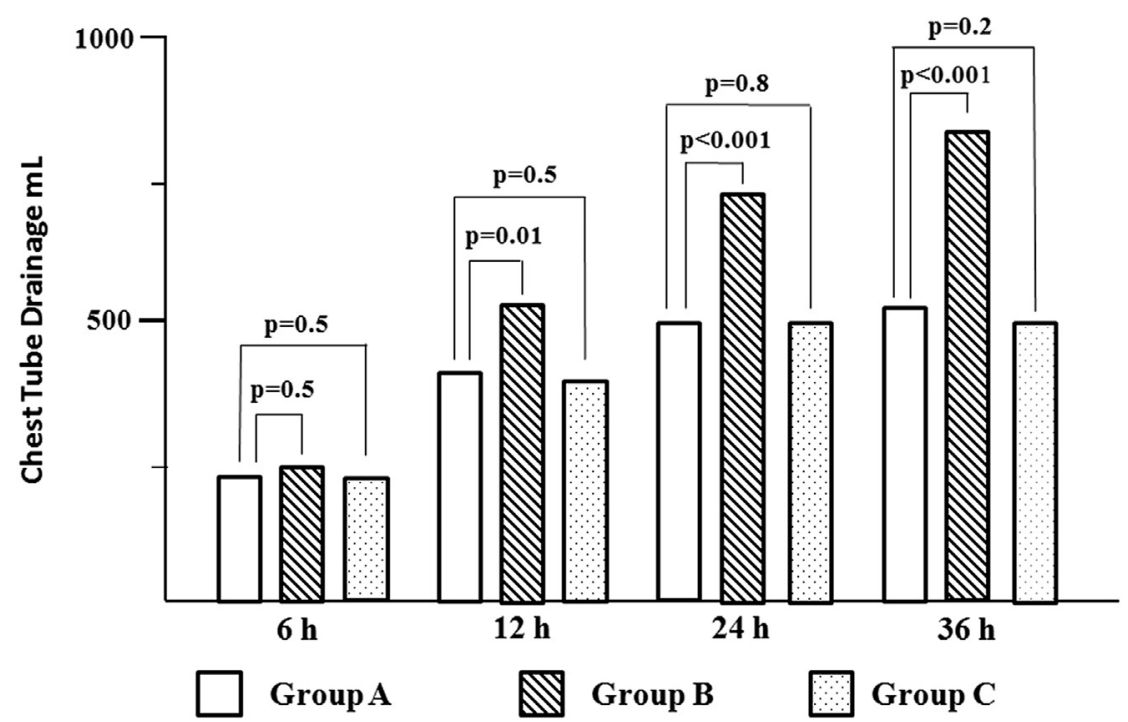

FIGURE 3. Postoperative chest tube drainage evaluated at $6,12,24$, and 36 hours. 
TABLE 4. Clinical outcome

\begin{tabular}{lccccc}
\hline & $\begin{array}{c}\text { Group A } \\
(\mathbf{n}=\mathbf{1 0 0})\end{array}$ & $\begin{array}{c}\text { Group B } \\
(\mathbf{n}=\mathbf{1 0 0})\end{array}$ & $\begin{array}{c}\text { Group C } \\
(\mathbf{n}=\mathbf{1 0 0})\end{array}$ & $\boldsymbol{P}^{*}$ & $\boldsymbol{P} \dagger$ \\
\hline Reoperation for bleeding & 1 & 2 & 1 & 1 & 1 \\
Deaths & 4 & 5 & 2 & .9 & .7 \\
Perioperative MI & 4 & 6 & 4 & .7 & 1 \\
Stroke & 1 & 1 & 0 & 1 & .9 \\
LOS & 4 & 5 & 3 & .9 & .9 \\
Renal failure & 2 & 3 & 2 & .9 & 1 \\
Sepsis & 1 & 0 & 0 & .9 & 1 \\
Sternal wound infections & 2 & 0 & 1 & .9 & .9 \\
\hline
\end{tabular}

Values are means \pm SD or numbers. MI, Myocardial infarction; LOS, low output syndrome; $S D$, standard deviation. ${ }^{*} P$ value for the comparison of group A versus group B. $\dagger P$ value for the comparison of group A versus group $\mathrm{C}$.

had a lower preoperative risk of bleeding compared with both randomized groups, these results tend to rule out the bias due to risk factors for bleeding other than clopidogrel in our study population. In all study groups, only $\sim 10 \%$ of patients, independent of the group, required FFP and/or blood cryoprecipitate transfusion as a possible consequence of our strict adherence to current guidelines ${ }^{20}$ and the preference for off-pump CABG which, unlike conventional CABG using cardiopulmonary bypass, provides favorable effects in preventing coagulation disorders. ${ }^{21,22}$

Our results highlight the wide interindividual variability in recovery time after clopidogrel withdrawal, which is a direct consequence of the wide range of individual responses to clopidogrel. By means of point-of-care platelet function testing, we identified a significant proportion of patients with normal platelet function, who could be operated early after hospital admission (within 1-2 days). Moreover, as more than one half of patients returned to baseline platelet reactivity within 5 days of clopidogrel discontinuation, it was interesting that approximately $20 \%$ of patients displayed persistent platelet inhibition and required from 6 to 8 days for complete recovery of platelet function after clopidogrel discontinuation. These findings are also supported by the recent article by Price and colleagues ${ }^{23}$ who reported that about $25 \%$ of patients had residual effects beyond a 5-day waiting period after clopidogrel suspension.

The evidence that a uniform waiting period may not benefit all patients needing CABG is supported also by the comparative evaluation of the bleeding rate and the need for blood product transfusion analyzed according to interquartile distribution of chest tube drainage. No significant differences were detected in the lower quartiles. By contrast, the analysis of the upper quartiles showed that patients in group B experienced significantly increased bleeding volume and need for PRBC transfusions, a tendency to more prolonged bleeding over the time, and a significantly longer postoperative hospitalization compared with patients in group A and group C. These findings may have considerable clinical implications because they likely support the hypothesis that persistent clopidogrel activity before CABG surgery significantly increases the hemorrhagic risk.

Several previous studies have suggested that bleeding and blood product transfusion expose patients to infectious complications, a need for mechanical ventilation, death, increased length of the hospital stay, and associated costs. ${ }^{11,24-27}$ Our study, however, is not powered enough to detect significant differences in mortality or clinical outcome among the groups. The limited numbers of index events, equally distributed, hindered any definitive assertions on this topic. Our results corroborate the recommendations of the 2011 Blood Conservation Clinical Practice Guidelines from the Society of Thoracic Surgeons/Society of Cardiovascular Anesthesiologists, reporting that the use of point-of-care testing might be reasonable to identify poor responders to clopidogrel who are candidates for early CABG and may not require a preoperative clopidogrel-free period. ${ }^{20}$ Moreover, we suggest that the indication for preoperative point-of-care testing could be expanded to identify those patients with residual platelet activity after clopidogrel withdrawal who need a longer waiting time to recover optimal platelet function.

In this study, use of aspirin was not suspended before surgery, which could carry a small but significant additional bleeding risk. To rule out the impact of this potential confounder, we evaluated aspirin in a multivariate analysis of risk factors for bleeding using all 300 study patients. In this model, aspirin was found to be a significant, although weak, independent risk factor for blood transfusion. By contrast, a further model, which analyzed chest tube drainage in patients who used aspirin and those who did not within each study group, failed to detect any significant interaction of aspirin with postoperative bleeding.

The main limitation of this study is its nonrandomized design. However, all patients were enrolled in a short time (13 months), were treated by the same staff following the same institutional standards, and carefully matched to reduce all confounders. Surgeons and anesthetists could be aware of the clopidogrel status and this knowledge may have influenced clinical decision making. However, a breakdown analysis by individual surgeons revealed uniformity in blood product use, which minimizes this opportunity for bias. Furthermore, it may be questionable to what extent the risk of bleeding can be attributed to clopidogrel rather than other bleeding risks. Nevertheless, although such residual bias might have occurred, we are confident that the homogeneous distribution of risk factors between group A and group B and the use of a control group with lower bleeding risk were sufficient to remove any misleading interference. Great attention has been paid to avoid intra- and/or postoperative dilution, delayed turnaround times of laboratory processing, and residual heparin activity, although the use of kaolin ACT may not be the best method to ensure complete neutralization of heparin. 
In conclusion, monitoring platelet function may provide an objective guideline to determine flexible timing of surgery in patients treated with clopidogrel compared with the current practice of unselected timing. This strategy reduced postoperative bleeding and consumption of blood products and was associated with shorter waiting time than recommended in the current guidelines.

The authors are grateful to Dr GiovanBattista Mannacio from the Department of Mathematics (Statistics Section), Imperial College London for assistance with the statistical analysis.

\section{References}

1. Levine GN, Bates ER, Blankenship JC, Bailey SR, Bittl JA, Cercek B, et al. 2011 ACCF/AHA/SCAI guideline for percutaneous coronary intervention: a report of the American College of Cardiology Foundation/American Heart Association Task Force on Practice Guidelines and the Society for Cardiovascular Angiography and Interventions. J Am Coll Cardiol. 2011;58:e44-122.

2. Jneid H, Anderson JL, Wright RS, Adams CD, Bridges CR, Casey DE Jr, et al. 2012 ACCF/AHA focused update of the guideline for the management of patients with unstable angina/non-ST-elevation myocardial infarction (updating the 2007 guideline and replacing the 2011 focused update): a report of the American College of Cardiology Foundation/American Heart Association Task Force on practice guidelines. J Am Coll Cardiol. 2012;60:645-81.

3. Angiolillo DJ, Fernandez-Ortiz A, Bernardo E, Alfonso F, Macaya C, Bass TA, et al. Variability in individual responsiveness to clopidogrel: clinical implications, management, and future perspectives. J Am Coll Cardiol. 2007;49: 1505-16.

4. Hillis LD, Smith PK, Anderson JL, Bittl JA, Bridges CR, Byrne JG, et al. 2011 ACCF/AHA guideline for coronary artery bypass graft surgery: executive summary: a report of the American College of Cardiology Foundation/American Heart Association Task Force on Practice Guidelines. J Thorac Cardiovasc Surg. 2012;143:4-34.

5. Ferraris VA, Saha SP, Oestreich JH. 2012 update to the Society of Thoracic Surgeons guideline on use of antiplatelet drugs in patients having cardiac and noncardiac operations. Ann Thorac Surg. 2012;94:1761-81.

6. Pollack CV Jr, Hollander JE, Chen AY, Peterson ED, Bangalore S, Peacock FW, et al. Non-ST-elevation myocardial infarction patients who present during off hours have higher risk profiles and are treated less aggressively, but their outcomes are not worse: a report from Can Rapid Risk Stratification of Unstable Angina Patients Suppress ADverse Outcomes with Early Implementation of the ACC/AHA Guidelines CRUSADE initiative. Crit Pathw Cardiol. 2009;8: 29-33.

7. Goodnough LT, Smith PK, Levy JH, Poston RS, Short MA, Weerakkody GJ, et al. Transfusion outcomes in patients undergoing coronary artery bypass grafting treated with prasugrel or clopidogrel: TRITON-TIMI 38 retrospective data analysis. J Thorac Cardiovasc Surg. 2013;145:1077-82.

8. Firanescu CE, Martens EJ, Schönberger JP, SolimanHamad MA, van Straten AH Postoperative blood loss in patients undergoing coronary artery bypass surgery after preoperative treatment with clopidogrel. A prospective randomised controlled study. Eur J Cardiothorac Surg. 2009;36:856-62.

9. Shim JK, Choi YS, Oh YJ, Bang SO, Yoo KJ, Kwak YL. Effects of preoperative aspirin and clopidogrel therapy on perioperative blood loss and blood transfusion requirements in patients undergoing off-pump coronary artery bypass graft surgery. J Thorac Cardiovasc Surg. 2007;134:59-64.

10. Nijjer SS, Watson G, Athanasiou T, Malik IS. Safety of clopidogrel being continued until the time of coronary artery bypass grafting in patients with acute coronary syndrome: a meta-analysis of 34 studies. Eur Heart J. 2011;32:2970-88.
11. Vaccarino GN, Thierer J, Albertal M, Vrancic M, Piccinini F, Benzadón M, et al. Impact of preoperative clopidogrel in off pump coronary artery bypass surgery: a propensity score analysis. J Thorac Cardiovasc Surg. 2009;137:309-13.

12. Leong JY, Baker RA, Shah PJ, Cherian VK, Knight JL. Clopidogrel and bleeding after coronary artery bypass graft surgery. Ann Thorac Surg. 2005;80:928-33.

13. Mannacio VA, Di Tommaso L, Antignano A, De Amicis V, Vosa C. Aspirin plus clopidogrel for optimal platelet inhibition following off-pump coronary artery bypass surgery: results from the CRYSSA (prevention of Coronary arteRY bypaSS occlusion After off-pump procedures) randomised study. Heart. 2012; 98:1710-5.

14. Ferraris VA, Ferraris SP, Saha SP, Hessel EA II, Haan CK, Royston BD, et al. Perioperative blood transfusion and blood conservation in cardiac surgery: the Society of Thoracic Surgeons and the Society of Cardiovascular Anesthesiologists clinical practice guideline. Ann Thorac Surg. 2007;83(5 Suppl):S27-86.

15. Jakubowski JA, Payne CD, Li YG, Brandt JT, Small DS, Farid NA, et al. The use of the VerifyNow P2Y12 point-of-care device to monitor platelet function across a range of P2Y12 inhibition levels following prasugrel and clopidogrel administration. Thromb Haemost. 2008;99:409-15.

16. Tsantes A, Ikonomidis I, Papadakis I, Kottaridi C, Tsante A, Kalamara E, et al. Evaluation of the role of the new INNOVANCE PFA P2Y test cartridge in detection of clopidogrel resistance. Platelets. 2012;23:481-9.

17. Wijns W, Kolh P, Danchin N, Di Mario C, Falk V, Folliguet T, et al. Guidelines on myocardial revascularization. The Task Force on Myocardial Revascularization of the ESC/EACTS. Eur Heart J. 2010;31:2501-55.

18. Thygesen K, Alpert JS, Jaffe AS, Simoons ML, Chaitman BR, White HD, the Writing Group on behalf of the Joint ESC/ACCF/AHA/WHF Task Force for the Universal Definition of Myocardial Infarction. Third universal definition of myocardial infarction. J Am Coll Cardiol. 2012;60:1581-98.

19. Mannacio V, Di Tommaso L, De Amicis V, Stassano P, Musumeci F, Vosa C. Preoperative intraaortic balloon pump for off-pump coronary arterial revascularization. Ann Thorac Surg. 2012;93:804-9.

20. Ferraris VA, Brown JR, Despotis GJ, Hammon JW, Reece TB, Saha SP, et al. 2011 Update to the Society of Thoracic Surgeons and the Society of Cardiovascular Anesthesiologists blood conservation clinical practice guidelines. Ann Thorac Surg. 2011;91:944-82.

21. Paparella D, Galeone A, Venneri MT, Coviello M, Scrascia G, Marraudino N, et al. Activation of the coagulation system during coronary artery bypass grafting: comparison between on-pump and off-pump techniques. J Thorac Cardiovasc Surg. 2006;131:290-7.

22. Englberger L, Immer FF, Eckstein FS, Berdat PA, Haeberli A, Carrel TP. Offpump coronary artery bypass operation does not increase procoagulant and fibrinolytic activity: preliminary results. Ann Thorac Surg. 2004;77:1560-6.

23. Price MJ, Walder JS, Baker BA, Heiselman DE, Jakubowski JA, Logan DK, et al. Recovery of platelet function after discontinuation of prasugrel or clopidogrel maintenance dosing in aspirin-treated patients with stable coronary disease: the recovery trial. J Am Coll Cardiol. 2012;59:2338-43.

24. Ranucci M, Aronson S, Dietrich W, Dyke CM, Hofmann A, Karkouti K, et al. Patient blood management during cardiac surgery: do we have enough evidence for clinical practice? J Thorac Cardiovasc Surg. 2011;142:249.e1-32.

25. Fox KA, Mehta SR, Peters R, Zhao F, Lakkis N, Gersh BJ. Benefits and risks of the combination of clopidogrel and aspirin in patients undergoing surgical revascularization for non-ST-elevation acute coronary syndrome: the Clopidogrel in Unstable angina to prevent Recurrent ischemic Events (CURE) Trial. Circulation. 2004;110:1202-8.

26. LaPar DJ, Crosby IK, Ailawadi G, Ad N, Choi E, Spiess BD, et al. Blood product conservation is associated with improved outcomes and reduced costs after cardiac surgery. J Thorac Cardiovasc Surg. 2013;145:796-803.

27. Ascione R, Ghosh A, Rogers C, Cohen A, Monk C, Angelini GD. In hospital patients exposed to clopidogrel before coronary artery bypass graft surgery: a word of caution. Ann Thorac Surg. 2005;79:1210-6. 